\title{
APPROPRIATENESS AND EFFECTIVENESS OF ADAPTED AEROBIC GYMNASTICS PROGRAMMES FOR STUDENTS WITH PARTIAL MEDICAL EXEMPTIONS
}

\author{
Diana Consuela MITU1* \\ ${ }^{1}$ National University of Physical Education and Sport, Faculty of Physical Education and Sport, \\ Bucharest, Romania \\ *Corresponding author: mitudiana@yahoo.com
}

https://doi.org/10.35189/dpeskj.2021.60.1.7

\begin{abstract}
The purpose of this research was to meet the needs of students with partial medical exemptions through adapted attractive and effective exercise programmes. The study was conducted on a sample consisting of 30 students with partial medical exemptions, who had the physician's recommendation to perform adapted physical exercise, and participation was based on their own consent. Participants were randomly divided into two groups of 15 subjects each. Both groups were included in a special aerobic gymnastics programme applied during physical education classes at university level. The experiment group additionally benefited from an aerobic exercise programme for independent activity. Initial and final tests were performed to determine vital capacity, static balance and speed-coordination. The analysis of the results showed statistically significant improvements between the initial and final tests (at a 0.05 significance threshold) in both groups for two of the three parameters, namely vital capacity and static balance. The comparative analysis of the final results achieved by the two groups highlighted a statistically significant improvement in the performance of the experiment group compared to the control group for the same two parameters (vital capacity and static balance), while for speed-coordination, the differences were statistically insignificant. We can conclude that the special aerobic gymnastics programmes designed by us have proven their effectiveness in improving some motor and functional parameters.
\end{abstract}

Keywords: aerobics, students, partial medical exemption.

\section{Introduction}

In the context of modern life, the individual has to face a multitude of challenges related to the harmful influences to which our bodies are subjected because of the increasing distance from the original coordinates of our phylogenetic development. How contemporary people lead their everyday lives is obviously in flagrant contradiction with the deep needs of any biological organism, which has been designed to live and develop in and through movement.

For this reason, against the background of a social life increasingly captured by the facilities and conveniences offered by the explosive development of science and technology, sedentary lifestyle and lack of exercise are identified as the main risk factors for public health.

In the White Paper on Sport, the European Commission (2007) has officially brought to the attention of Member States that insufficient physical activity is a problem that entails significant risks for public health. Lack of exercise leads to an increased incidence of overweight and obesity, cardiovascular disease and diabetes, and their negative effects affect both people's lives and the budgets and economies of states.

In this regard, the European Commission (2008) warns, in the EU Physical Activity Guidelines Recommended Policy Actions in Support of Health-Enhancing Physical Activity, about the tendency of European children to spend more and more time in sedentary activities, 
which generates increased risks related to a multitude of physical, metabolic and mental morbid conditions. In order to counteract this situation, the European Commission points out the importance of taking action in the educational environment, specifying that it has been found that approximately $80 \%$ of children and young people practice physical exercise only at school.

As regards the adult population, the New Eurobarometer on Sport and Physical Activity (European Commission, 2018) shows that half of Europeans exercise or play sport, but many never engage in physical activity. The report indicates that, compared to the previous 2014 Eurobarometer survey, the proportion of Europeans who say they never exercise or play sport has slightly increased from $42 \%$ to $46 \%$, and this is a continuation of a gradual trend since 2009. According to the Eurobarometer data, $63 \%$ of the Romanian population never exercise or play sport, which puts our country in a worrying 4th place out of the 29 EU countries in terms of sedentary lifestyle.

Recognising the beneficial effects of exercise on health, Member States of the World Health Organisation (WHO) have agreed on a $10 \%$ relative decrease in the prevalence of insufficient physical activity by 2025 , as one of the nine global targets to improve the prevention and treatment of non-communicable diseases. In a study including almost 2 million participants from 168 countries (representing 96\% of the world's population), Guthold et al. (2018) showed that, in 2016, more than a quarter of adults did not perform enough physical activity.

In the United States, the effects of insufficient physical activity are highlighted by Finkelstein et al. (2003). According to them, more than half of Americans are either overweight or obese, and the prevalence of overweight and obesity has increased by $12 \%$ and $70 \%$, respectively, in the last decade. The authors computed aggregate medical spending attributable to overweight and obesity and have found that they are comparable to smoking-attributable healthcare spending, wondering in this context why government campaigns against problems caused by overweight and obesity are not as tenacious as those against smoking. Wiklund (2016) shows that the increasing spread of obesity occurs against the background of a continuous decrease in energy expenditure necessary for everyday life, in the conditions of eating habits that favour excessive energy intake, but regular physical activity has the potential to solve this problem.

Sharif and Sargent (2006) point out that, in the United States, children spend 40 hours a week consuming various forms of media (television, movies or videos), a situation that they correlate with high risks of obesity and aggression as well as health-risk behaviours. The authors show that adolescents with low self-esteem and high levels of rebelliousness or sensation-seeking have increased media exposure. They also found a strong relationship between media exposure measures and poor academic performance. According to Feldman et al. (2003), the time spent on watching television and playing video games was not associated with a decrease in physical activity. Physical activity was not inversely associated with watching television or playing video games but was positively associated with productive sedentary behaviour and part-time work.

Riebe et al. (2015), supporting the new recommendations of the American College of Sports Medicine (ACSM) for exercise preparticipation health screening, highlight that there is considerable evidence that exercise is safe for most people and has many associated health and fitness benefits. The authors add that the cardiovascular risks associated with exercise diminish as individuals become more physically active/fit. 
Myers et al. (2004) from the California School of Medicine (USA) studied the effects of physical activity on mortality in men, showing that a 1,000-kcal/week increase in energy consumption would reduce the risk of cardiovascular mortality by up to $20 \%$. Soares-Miranda et al. (2016) also concluded that walking at a fast pace (over $5 \mathrm{~km} / \mathrm{h}$ ) would reduce the risk of developing coronary heart disease and stroke. Lear et al. (2017) highlighted that 1 in 20 cases of cardiovascular disease and 1 in 12 cases of premature death could be prevented worldwide with the help of regular physical activity (at least 150 minutes of physical activity per week, according to WHO recommendations).

Helmrich et al. (1991) show that exercise has beneficial effects even on those who are already diagnosed with diabetes mellitus, reducing the risk of premature mortality by $39 \%$ to $54 \%$. The most effective forms of physical activity to keep diabetes under control, as identified by the authors mentioned above, would be aerobic physical activity and endurance training.

At the Loma School of Public Health (SUA), Martin et al. (2009) demonstrated the role of moderate-intensity exercise in improving the immune function and reducing the risk and severity of respiratory viral infection. Exercising subjects recorded shorter infectious episodes compared to sedentary people. Nieman and Wentz (2019) also highlight the protective effect of moderate physical activity on the risk of disease in contrast to the increased risk of disease that appears to be related to prolonged and intensive exercise.

It can be seen from the above that, beyond the widely recognised influence of physical activity on strengthening health and reducing the risk of disease, numerous studies have pointed out that subjects with various minor medical conditions can also benefit from well-designed and properly dosed physical exercise.

Based on this finding, we considered that students with partial medical exemptions should be included in customised physical activity programmes adapted in terms of motor structure, volume, intensity and complexity. Thus, they can safely enjoy the benefits of exercise without feeling embarrassed by the low level of their motor capacity compared to that of their colleagues with no medical problems. This approach meets the recommendations made by the European Commission (2015) in the EU Work Plan for Sport 2014-2017. With regard to exemptions from physical education, the Commission recommends finding creative ways of organisation so as to ensure the necessary conditions to increase exercise participation of this category of young people by using inclusive, differentiated and adapted activities.

From our point of view, the inclusion of students with partial medical exemptions in specific exercise programmes did not particularly aim to optimise physical parameters and achieve motor performance, but primarily to raise awareness of the benefits provided by exercise in the sense of alleviating some medical conditions and strengthening health. In the case of these students, we considered that surpassing themselves was more important than their performance quantified in numbers.

\section{Research purposes}

- Attracting the largest possible number of students with partial medical exemptions to the practice of physical exercise organised within the faculty or independently.

- Finding the best ways to meet the particular needs of students with partial medical exemptions. 
- Designing and implementing a training programme based on streamlined and structured means specific to aerobic gymnastics in order to expand the aerobic gymnastics contents of the Physical Education subject at the "Carol Davila" University of Medicine and Pharmacy (UMF) in Bucharest.

- Designing and implementing an aerobic gymnastics programme with specific exercises for independent activity in order to reduce the negative consequences of the medically exempt status on the young student's personality.

- Educating future physicians in the sense of attracting them to the independent practice of exercise so that, in turn, they can recommend physical exercise to patients, as a very important prophylactic means.

\section{Objectives and tasks}

- Establishing the structure and contents of exercise programmes adapted to the needs of students with partial medical exemptions, in terms of activity performed both during physical education classes and additionally, as independent physical activity.

- Improving the health status of the largest possible number of medically exempt students who are able to perform a certain type of minimal physical effort.

- Optimising the "wellbeing" of these students through progressive physical movements, knowing that, through movement, the human brain releases endorphins that generate a state of optimism and good mood, which leads to an increase in the quality of life.

- Increasing endurance, with beneficial transfer in their future professional activity.

\section{Hypotheses}

H1: Practising special aerobic gymnastics programmes leads to a significant improvement in vital capacity and static balance for students with partial medical exemptions.

$\mathrm{H} 2$ : Practising special aerobic gymnastics programmes leads to a significant improvement in speed-coordination for students with partial medical exemptions.

\section{Methodology}

\section{Participants}

The study was conducted on a sample consisting of 30 first- and second-year students with partial medical exemptions from the "Carol Davila" UMF Bucharest, in the gym of the university. All 30 students had the physician's recommendation to perform adapted physical exercise, and participation in the study was based on their own consent.

\section{Procedure}

The experiment was designed to take place between October 2019 and June 2020. However, because of the exceptional conditions caused by the pandemic, which suspended teaching 
activities in the education establishment, it could not be completed within the initially proposed parameters but ended as a matter of urgency in March 2020. The statistical analysis and interpretation of data were performed between May and June 2020.

Specific aerobic gymnastics programmes adapted to the needs of UMF students with partial medical exemptions

In the experiment, we designed and used four aerobic gymnastics programmes consisting of exercises adapted to the needs of students with partial medical exemptions as follows:

- Two aerobic gymnastics programmes used during physical education and sport classes, which were performed by both groups (experiment and control). Through these programmes, we first aimed to teach students the basic steps of aerobic gymnastics, and then simple 32-count (C) choreography combinations with specific steps performed to musical accompaniment.

- Two additional aerobic gymnastics programmes that students in the experiment group had as individual work at home. These two programmes consisted of choreography pieces where the basic steps were used, but also exercises for correct body posture and mobility exercises for the trunk and spinal muscles, correlated with breathing.

We exemplify below the structure and some content elements for each of the two types of programmes used (Table 1 and Table 2).

Table 1. Example of a specific aerobic gymnastics programme used during lessons

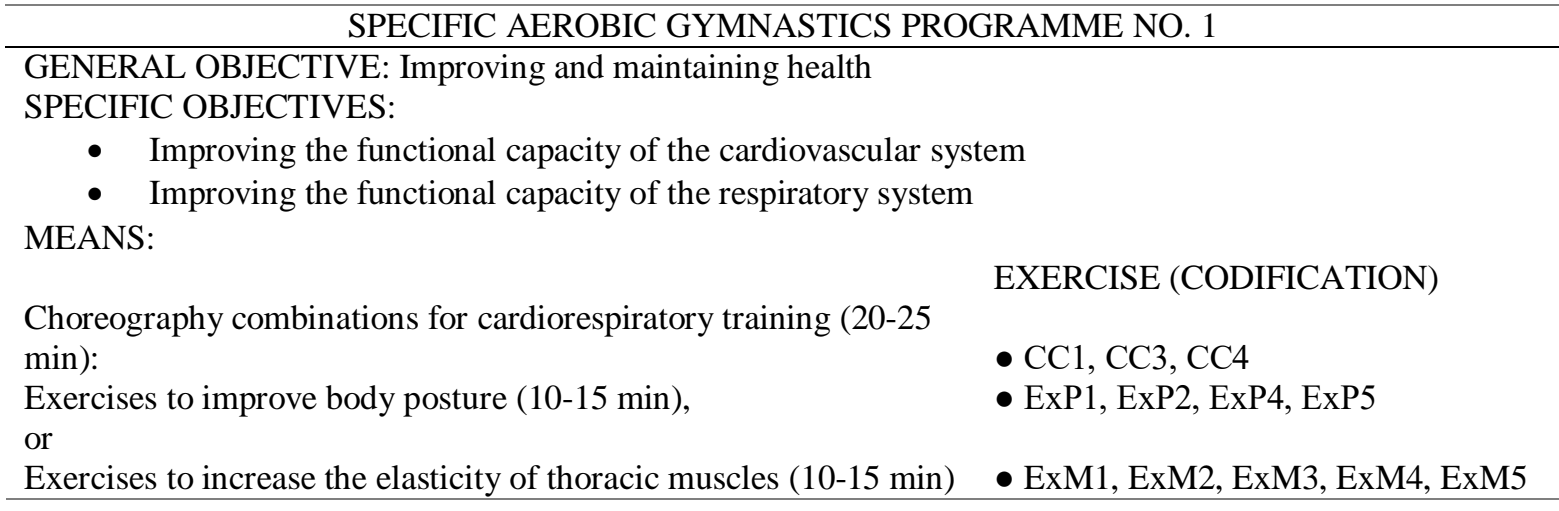

Table 2. Example of a specific programme for individual work SPECIFIC PROGRAMME FOR INDIVIDUAL WORK NO. 2

GENERAL OBJECTIVE: Harmonious physical development

SPECIFIC OBJECTIVES: Development of muscle elasticity and joint mobility MEANS:

Choreography combinations for cardiorespiratory training (20-25 $\min$ ):

EXERCISE (CODIFICATION)

Exercises to improve body posture (10-15 min),

- $\mathrm{CC} 2, \mathrm{CC} 3, \mathrm{CC} 4$

or

- ExP7, ExP8, ExP9, ExP10, ExP11

Exercises to increase the elasticity of thoracic muscles (10-15 min)

ExM6, ExM7, ExM8, ExM9, ExM10 
Examples of exercises used in the programmes:

- Choreography combinations with steps specific to aerobic gymnastics (CC):

$\begin{array}{clc}\text { CC 1: } & \text { - March forward } & 1 \times 8-C \\ & \text { - March backwards } & 1 \times 8-C \\ & \text { - March in place to straddle } & 1 \times 8-C \\ & \text { - Side lunge } & 1 \times 8-C \\ \text { CC 2: } & \text { - Step touch } & 1 \times 8-C \\ & \text { - V-step } & 1 \times 8-C \\ & \text { - March in place } & 1 \times 8-C \\ & \text { - Right/Left back lunge } & 1 \times 8-C\end{array}$

- Posture and proper body alignment exercises (PEx):

PEx 1: - From standing with your feet parallel at hip-width apart in conditions of proper postural alignment, raise your arms while inhaling and lower them sideways while exhaling 10 repetitions;

PEx 7: - From standing on your left foot, take a medium step with the right foot while carrying your arms sideways, bend your trunk laterally to the right and return to standing - 10 repetitions;

- With hands behind your head, elbows sideways, turn to the right and return to standing - 10 repetitions.

- Mobility exercises for the trunk and spinal muscles, correlated with breathing (MEx):

MEx 4: - From support on your knees and palms, contract your abdominal muscles and stretch your back muscles while exhaling through your mouth and arch your spine, followed by the contraction of your back muscles while inhaling through your nose (with an emphasis on the control of movements and their synchronisation with breathing) - 10 repetitions;

MEx 6: - From support on your knees and palms, lower your buttocks to your heels, carry your palms as far from your knees as possible while stretching the muscles of your trunk and arms; $\mathrm{C} 1$ - Arch your back while exhaling through your mouth and return to support on your knees; C2 - Transition to support on your palms with trunk extension and inhalation through the nose; C3 - Arch your back while lowering your chin to the chest and exhalation; C4 - Keep your spine arched and lower your buttocks to your heels with deep exhalation - 6 repetitions.

In the experiment, we used the following tests to measure:

- Vital capacity (VC) - was determined by the Spirometry test.

- Static balance - was determined by the Flamingo test (modified) from the Eurofit test battery. The ability to maintain balance for 60 seconds while standing on one leg, barefoot, with the other leg stretched sideways. The number of imbalances during which the free leg touched the floor was recorded.

- Speed-coordination - was determined by the Shuttle Run test performed while carrying objects and using various ways of travel (the route was covered twice, back and forth):

- A 3-m sided square is drawn on the ground;

- A rubber cone is placed in each corner, and two cones are placed at the start;

- The student is standing at the starting corner 1 ;

- At the sound signal, the student picks up a cone, runs facing corner 2 and changes the cone; 
- Step touch travel to the left to corner 3 - the student changes the cone;

- Backward running to corner 4 - the student changes the cone;

- Step touch travel to the right to corner 1 - the student changes the cone;

- Then, the route is travelled again in the opposite direction, with the same tasks.

- Execution time is recorded in seconds.

\section{Results}

The average results achieved by the two groups in the initial and final tests are shown in Table 3.

Table 3. Average results achieved by the two groups in the initial and final tests

\begin{tabular}{lcccccc}
\hline & \multicolumn{2}{c}{ Spirometry $(\mathrm{ml})$} & \multicolumn{2}{c}{ Flamingo (imbalances) } & \multicolumn{2}{c}{ Shuttle Run (sec) } \\
\cline { 2 - 7 } & Initial & Final & Initial & Final & Initial & Final \\
\cline { 2 - 7 } Control group (C) & 2563 & 2810 & 6.73 & 5.60 & 19.90 & 19.48 \\
Experiment group (E) & 2519 & 2881 & 4.93 & 4.07 & 19.65 & 19.41 \\
\hline
\end{tabular}

Processing and interpretation of the results for the experiment group

The statistical indicators for the Spirometry test can be seen in Table 4.

Table 4. Statistical indicators, Experiment group - Spirometry

\begin{tabular}{lcc}
\hline \multicolumn{1}{c}{ Statistical indicators } & IT & FT \\
\hline Mean & 2519 & 2881 \\
Median & 2500 & 2860 \\
Standard deviation & 111 & 68 \\
Minimum & 2300 & 2780 \\
Maximum & 2700 & 2990 \\
Range & 400 & 210 \\
Coefficient of variation & $4.4 \%$ & $2.4 \%$ \\
\hline
\end{tabular}

\begin{tabular}{llc}
\hline \multicolumn{1}{c}{ Statistical indicators } & \multicolumn{2}{c}{ FT-IT differences } \\
\hline Mean difference & \multicolumn{2}{c}{362} \\
Progress rate & $14.4 \%$ \\
95\% Confidence interval & $(288 ; 438)$ \\
& $\mathrm{t}$ & 10.37 \\
Paired-samples t-test & $\mathrm{df}$ & 14 \\
& $\mathrm{p}$ & $<0.001$ \\
Effect size & & 2.68 \\
\hline
\end{tabular}

The mean value achieved by the experiment group for Spirometry increased by $362 \mathrm{ml}$ (14.4\%), from 2519 in the initial test to $2881 \mathrm{ml}$ in the final test. The confidence interval for the mean difference is $(288 ;-438)$. The distribution of the results is homogenous in both tests. The effect size (2.68) indicates a very large mean difference. The mean difference is statistically significant, as the significance threshold has the $\mathrm{p}$-value $<0.001<0.05$ for $\mathrm{t}=$ 10.37 and 14 degrees of freedom. A synthetic statistical analysis of the results for the Spirometry test is shown in Table 5.

Table. 5. Summary of the Spirometry test, Experiment group - Mean difference (TF - TI)

\begin{tabular}{cccccc}
\hline Mean difference $(\mathrm{F}-\mathrm{I})$ & Progress rate & $\mathrm{t}$ & $\mathrm{p}$ & Difference & Null hypothesis \\
\hline $\mathbf{3 6 2}$ & $14.4 \%$ & 10.37 & $<0.001$ & $\begin{array}{c}\text { very large and } \\
\text { statistically significant }\end{array}$ & rejected \\
& & & &
\end{tabular}


The statistical indicators for the Flamingo test can be seen in Table 6 .

Table 6. Statistical indicators, Experiment group - Flamingo

\begin{tabular}{lcc}
\hline Statistical indicators & IT & FT \\
\hline Mean & 4.93 & 4.07 \\
Median & 5 & 4 \\
Standard deviation & 1.03 & 1.03 \\
Minimum & 3 & 2 \\
Maximum & 7 & 6 \\
Range & 4 & 4 \\
Coefficient of variation & $20.9 \%$ & $25.4 \%$ \\
\hline
\end{tabular}

\begin{tabular}{llc}
\hline \multicolumn{1}{c}{ Statistical indicators } & \multicolumn{2}{c}{ FT-IT differences } \\
\hline Mean difference & & -0.86 \\
Progress rate & & $17.6 \%$ \\
95\% Confidence interval & $(-1.22 ;-0.51)$ \\
& $\mathrm{t}$ & 5.25 \\
Paired-samples t-test & $\mathrm{df}$ & 14 \\
& $\mathrm{p}$ & $<0.001$ \\
Effect size & & 1.35 \\
\hline
\end{tabular}

In the Flamingo test, the average number of imbalances for the experiment group decreased by 0.86 imbalances (17.6\%), from 4.93 in the initial test to 4.07 imbalances in the final test. The confidence interval for the mean difference is $(-1.22 ;-0.51)$. The results are relatively homogeneously distributed in both tests. The effect size (1.35) indicates a very large mean difference. The mean difference is statistically significant, as the significance threshold has the $\mathrm{p}$-value $<0.001<0.05$ for $\mathrm{t}=5.25$ and 14 degrees of freedom. A synthetic statistical analysis of the results for the Flamingo test is shown in Table 7.

Table 7. Summary of the Flamingo test, Experiment group - Mean difference (TF - TI)

\begin{tabular}{cccccc}
\hline Mean difference $(\mathrm{F}-\mathrm{I})$ & Progress rate & $\mathrm{t}$ & $\mathrm{p}$ & Difference & Null hypothesis \\
\hline $\mathbf{- 0 . 8 6}$ & $17.6 \%$ & 5.25 & $<0.001$ & $\begin{array}{c}\text { very large and statistically } \\
\text { significant }\end{array}$ & rejected \\
\hline
\end{tabular}

The statistical indicators for the Shuttle Run test can be seen in Table 8 .

Table 8. Statistical indicators, Experiment group - Shuttle Run

\begin{tabular}{lcc}
\hline \multicolumn{1}{c}{ Statistical indicators } & IT & FT \\
\hline Mean & 19.65 & 19.41 \\
Median & 20.10 & 19.90 \\
Standard deviation & 1.04 & 1.22 \\
Minimum & 17.36 & 17.10 \\
Maximum & 21.44 & 21.43 \\
Range & 4.08 & 4.33 \\
Coefficient of variation & $5.3 \%$ & $6.3 \%$ \\
\hline
\end{tabular}

\begin{tabular}{llc}
\hline \multicolumn{1}{c}{ Statistical indicators } & \multicolumn{2}{c}{ FT-IT differences } \\
\hline Mean difference & & -0.24 \\
Progress rate & $1.2 \%$ \\
95\% Confidence interval & $(-0.49 ; 0.02)$ \\
& $\mathrm{t}$ & 1.97 \\
Paired-samples t-test & $\mathrm{df}$ & 14 \\
& $\mathrm{p}$ & 0.068 \\
Effect size & & 0.51 \\
\hline
\end{tabular}

In the Shuttle Run test, the average time achieved by the experiment group decreased by $0.24 \mathrm{sec}(1.2 \%)$, from 19.65 in the initial test to $19.41 \mathrm{sec}$ in the final test. The confidence interval for the mean difference is $(-0.49 ; 0.02)$. The results are homogeneously distributed around the mean in both tests. The mean difference is statistically insignificant, as the significance threshold has the $\mathrm{p}$-value $=0.068>0.05$ for $\mathrm{t}=1.97$ and 14 degrees of freedom . A synthetic statistical analysis of the results for the Shuttle Run test is shown in Table 9. 
Table 9. Summary of the Shuttle Run test, Experiment group - Mean difference (FT - IT)

\begin{tabular}{cccccc}
\hline Mean difference (F-I) & Progress rate & $\mathrm{t}$ & $\mathrm{p}$ & Difference & Null hypothesis \\
\hline $\mathbf{- 0 . 2 4}$ & $1.2 \%$ & 1.97 & 0.068 & $\begin{array}{c}\text { medium to large and } \\
\text { statistically insignificant }\end{array}$ & accepted \\
\hline
\end{tabular}

Processing and interpretation of the results for the control group

The statistical indicators for the Spirometry test can be seen in Table 10.

Table 10. Statistical indicators, Control group - Spirometry

\begin{tabular}{lcc}
\hline \multicolumn{1}{c}{ Statistical indicators } & IT & FT \\
\hline Mean & 2563 & 2810 \\
Median & 2550 & 2800 \\
Standard deviation & 93 & 74 \\
Minimum & 2400 & 2700 \\
Maximum & 2700 & 2960 \\
Range & 300 & 260 \\
Coefficient of variation & $3.6 \%$ & $2.6 \%$ \\
\hline
\end{tabular}

\begin{tabular}{llc}
\hline \multicolumn{1}{c}{ Statistical indicators } & \multicolumn{2}{c}{ FT-IT differences } \\
\hline Mean difference & \multicolumn{2}{c}{247} \\
Progress rate & \multicolumn{2}{c}{$9.6 \%$} \\
95\% Confidence interval & \multicolumn{2}{c}{$(221 ; 272)$} \\
& $\mathrm{t}$ & 20.80 \\
Paired-samples t-test & $\mathrm{df}$ & 14 \\
& $\mathrm{p}$ & $<0.001$ \\
Effect size & & 5.37 \\
\hline
\end{tabular}

The mean value achieved by the control group for Spirometry increased by $247 \mathrm{ml}(9.6 \%)$, from 2563 in the initial test to $2810 \mathrm{ml}$ in the final test. The confidence interval for the mean difference is $(221 ; 272)$. The results are homogeneously distributed in both tests. The effect size indicates a very large mean difference. The mean difference is statistically significant, as the significance threshold has the $\mathrm{p}$-value $<0.001<0.05$ for $\mathrm{t}=20.80$ and 14 degrees of freedom. A synthetic statistical analysis of the results for the Spirometry test is shown in Table 11.

Table 11. Summary of the Spirometry test, Control group - Mean difference (FT - IT)

\begin{tabular}{cccccc}
\hline Mean difference (F-I) & Progress rate & $\mathrm{t}$ & $\mathrm{p}$ & Difference & Null hypothesis \\
\hline $\mathbf{2 4 7}$ & $9.6 \%$ & 20.80 & $<0.001$ & $\begin{array}{c}\text { very large and } \\
\text { statistically significant }\end{array}$ & rejected \\
\hline
\end{tabular}

The statistical indicators for the Flamingo test can be seen in Table 12.

Table 12. Statistical indicators, Control group - Flamingo

\begin{tabular}{lcc}
\hline \multicolumn{1}{c}{ Statistical indicators } & IT & FT \\
\hline Mean & 6.73 & 5.60 \\
Median & 7 & 6 \\
Standard deviation & 1.62 & 1.40 \\
Minimum & 3 & 2 \\
Maximum & 9 & 7 \\
Range & 6 & 5 \\
Coefficient of variation & $24.1 \%$ & $25.1 \%$ \\
\hline
\end{tabular}

\begin{tabular}{lcc}
\hline \multicolumn{1}{c}{ Statistical indicators } & FT-IT differences \\
\hline Mean difference & & -1.13 \\
Progress rate & $16.8 \%$ \\
95\% Confidence interval & $(-1.64 ;-0.63)$ \\
& $\mathrm{t}$ & 4.79 \\
Paired-samples t-test & $\mathrm{df}$ & 14 \\
& $\mathrm{p}$ & $<0.001$ \\
Effect size & & 1.24 \\
\hline
\end{tabular}


In the Flamingo test, the average number of imbalances for the control group decreased by 1.13 imbalances (16.8\%), from 6.73 in the initial test to 5.60 imbalances in the final test. The confidence interval for the mean difference is $(-1.64 ;-0.63)$. The results are relatively homogeneously distributed in both tests. The effect size (1.24) indicates a very large mean difference. The mean difference is statistically significant, as the significance threshold has the $\mathrm{p}$-value $<0.001<0.05$ for $\mathrm{t}=4.79$ and 14 degrees of freedom. A synthetic statistical analysis of the results for the Flamingo test is shown in Table 13.

Table 13. Summary of the Flamingo test, Control group - Mean difference (FT - IT)

\begin{tabular}{cccccc}
\hline Mean difference (F-I) & Progress rate & $\mathrm{t}$ & $\mathrm{p}$ & Difference & Null hypothesis \\
\hline $\mathbf{- 1 . 1 3}$ & $16.8 \%$ & 4.79 & $<0.001$ & $\begin{array}{c}\text { very large and statistically } \\
\text { significant }\end{array}$ & rejected \\
\hline
\end{tabular}

The statistical indicators for the Shuttle Run test can be seen in Table 14.

Table 14. Statistical indicators, Control group - Shuttle Run

\begin{tabular}{lcc}
\hline \multicolumn{1}{c}{ Statistical indicators } & IT & FT \\
\hline Mean & 19.90 & 19.48 \\
Median & 19.50 & 19.18 \\
Standard deviation & 1.51 & 1.39 \\
Minimum & 17.00 & 17.05 \\
Maximum & 23.54 & 23.12 \\
Range & 6.54 & 6.07 \\
Coefficient of variation & $7.6 \%$ & $7.2 \%$ \\
\hline
\end{tabular}

\begin{tabular}{llc}
\hline \multicolumn{1}{c}{ Statistical indicators } & \multicolumn{2}{c}{ FT-IT differences } \\
\hline Mean difference & & -0.42 \\
Progress rate & $2.1 \%$ \\
95\% Confidence interval & $(-0.85 ; 0.01)$ \\
& $\mathrm{t}$ & 2.12 \\
Paired-samples t-test & df & 14 \\
& $\mathrm{p}$ & 0.053 \\
Effect size & & 0.55 \\
\hline
\end{tabular}

In the Shuttle Run test, the average time achieved by the control group decreased by 0.42 $\sec (2.1 \%)$, from 19.90 in the initial test to $19.48 \mathrm{sec}$ in the final test. The confidence interval for the mean difference is $(-0.85 ; 0.01)$. The results are homogeneously distributed in both tests. The mean difference is statistically insignificant, as the significance threshold has the p-value $=0.053>0.05$ for $\mathrm{t}=2.12$ and 14 degrees of freedom (we mention that the $\mathrm{p}$-value is very close to the 0.05 threshold, which is why further research on larger samples is required to get a clearer insight into the impact of the intervention programme on speed-coordination). A synthetic statistical analysis of the results for the Shuttle Run test is shown in Table 15.

Table 15. Summary of the Shuttle Run test, Control group-Mean difference (FT - IT)

\begin{tabular}{cccccc}
\hline Mean difference (F-I) & Progress rate & $\mathrm{t}$ & $\mathrm{p}$ & Difference & Null hypothesis \\
\hline $\mathbf{- 0 . 4 2}$ & $2.1 \%$ & 2.12 & 0.053 & $\begin{array}{c}\text { medium to large and } \\
\text { statistically insignificant }\end{array}$ & accepted \\
\hline
\end{tabular}

Comparative processing and interpretation of the results achieved by the two groups (Experiment vs. Control) in the final test

The statistical indicators for the Spirometry test can be seen in Table 16. 
Table 16. Comparative statistical indicators - Spirometry

\begin{tabular}{lcc}
\hline \multicolumn{1}{c}{ Statistical indicators } & Experiment & Control \\
\hline Mean & 2881 & 2810 \\
Median & 2860 & 2800 \\
Standard deviation & 68.2 & 73.8 \\
Minimum & 2780 & 2700 \\
Maximum & 2990 & 2960 \\
Range & 210 & 260 \\
Coefficient of variation & $2.4 \%$ & $2.4 \%$ \\
\hline
\end{tabular}

\begin{tabular}{lll}
\hline Mean difference (E - C) & & 71 \\
Mean difference (\%) & & $2.5 \%$ \\
STATISTICAL TESTS & & \\
Levene's test & Sig. & Equal \\
& 0.781 & distributions \\
Paired-samples t-test & $\mathrm{t}$ & $\mathrm{p}$ \\
Effect size & 2.749 & 0.010 \\
\hline
\end{tabular}

The average result for Spirometry is $71 \mathrm{ml}(2.5 \%)$ higher in the case of the experiment group. The averages of the two samples are $2881 \mathrm{ml}$ for the experiment group and $2810 \mathrm{ml}$ for the control group. The independent t-test shows that the mean difference is statistically significant, as the $\mathrm{p}$-value $=0.010<0.05$ for $\mathrm{t}=2.749$ and $\mathrm{df}=28$. The effect size index $(1.00)$ reveals shows that the mean difference is large to very large. A synthetic comparative statistical analysis of the final results for the two groups in the Spirometry test is shown in Table 17.

Table 17. Summary of the comparative analysis, Spirometry - Final mean difference $(E-C)$

\begin{tabular}{cccc}
\hline Mean difference $(\mathrm{E}-\mathrm{C})$ & Mean difference & Effect size & Null hypothesis \\
\hline $\mathbf{7 1}(\mathbf{2 . 5 \%})$ & statistically significant & large to very large & rejected \\
\hline
\end{tabular}

The statistical indicators for the Flamingo test can be seen in Table 18.

Table 18. Comparative statistical indicators - Flamingo

\begin{tabular}{lcc}
\hline \multicolumn{1}{c}{ Statistical indicators } & Experiment & Control \\
\hline Mean & 4.07 & 5.60 \\
Median & 4 & 6 \\
Standard deviation & 1.03 & 1.40 \\
Minimum & 2.0 & 2.0 \\
Maximum & 6.0 & 7.0 \\
Range & 4.0 & 5.0 \\
Coefficient of variation & $25.4 \%$ & $25.4 \%$ \\
\hline
\end{tabular}

\begin{tabular}{lll}
\hline Mean difference (E - C) & & -1.53 \\
$\begin{array}{l}\text { Mean difference (\%) } \\
\text { STATISTICAL TESTS }\end{array}$ & & $37.7 \%$ \\
& Sig. & Equal \\
Levene's test & 0.282 & distributions \\
& $\mathrm{t}$ & $\mathrm{p}$ \\
Paired-samples t-test & 3.407 & 0.002 \\
Effect size & & 1.24 \\
\hline
\end{tabular}

In the Flamingo test, the average number of imbalances is lower by 1.53 imbalances $(37.7 \%)$ for the experiment group. The averages of the two samples are 4.07 imbalances for the experiment group and 5.60 imbalances for the control group. The two samples have equal distributions, with $\mathrm{Sig}=0.282>0.05$, according to Levene's test. The independent t-test shows that the mean difference is statistically significant, as the $\mathrm{p}$-value $=0.002<0.05$ for $\mathrm{t}=3.407$ and $\mathrm{df}=28$. The effect size (1.24) reveals that the mean difference is very large. A synthetic comparative statistical analysis of the final results for the two groups in the Flamingo test is shown in Table 19.

Table 19. Summary of the comparative analysis, Flamingo - Final mean difference $(E-C)$

\begin{tabular}{cccc}
\hline Mean difference $(\mathrm{E}-\mathrm{C})$ & Mean difference & Effect size & Null hypothesis \\
\hline $\mathbf{- 1 . 5 3 ( 3 7 . 7 \% )}$ & statistically significant & very large & rejected \\
\hline
\end{tabular}


The statistical indicators for the Shuttle Run test can be seen in Table 20.

Table 20. Comparative statistical indicators - Shuttle Run

\begin{tabular}{lcc}
\hline \multicolumn{1}{c}{ Statistical indicators } & Experiment & Control \\
\hline Mean & 19.41 & 19.48 \\
Median & 19.90 & 19.18 \\
Standard deviation & 1.22 & 1.39 \\
Minimum & 17.1 & 17.1 \\
Maximum & 21.4 & 23.1 \\
Range & 4.3 & 6.1 \\
Coefficient of variation & $6.3 \%$ & $6.3 \%$ \\
\hline
\end{tabular}

\begin{tabular}{lll}
\hline Mean difference (E - C) & & -0.07 \\
Mean difference (\%) & & $0.3 \%$ \\
STATISTICAL TESTS & & \\
Levene's test & Sig. & Equal \\
& 0.984 & distributions \\
Paired-samples t-test & $\mathrm{T}$ & $\mathrm{p}$ \\
Effect size & 0.132 & 0.896 \\
\hline
\end{tabular}

In the Shuttle Run test, the average time is $0.07 \mathrm{sec}(0.3 \%)$ shorter for the experiment group. The averages of the two samples are $19.41 \mathrm{sec}$ for the experiment group and $19.48 \mathrm{sec}$ for the control group. The two samples have equal distributions, with $\mathrm{Sig}=0.984>0.05$, according to Levene's test. The independent t-test shows that the mean difference is statistically insignificant, as the $\mathrm{p}$-value $=0.896>0.05$ for $\mathrm{t}=0.132$ and $\mathrm{df}=28$. A synthetic comparative statistical analysis of the final results for the two groups in the Shuttle Run test is shown in Table 21.

Table 21. Summary of the comparative analysis, Shuttle Run-Final mean difference $(E-C)$

\begin{tabular}{cccc}
\hline Mean difference $(\mathrm{E}-\mathrm{C})$ & Mean difference & Effect size & Null hypothesis \\
\hline $\mathbf{- 0 . 0 7}(\mathbf{0 . 3 \%})$ & statistically insignificant & very small & accepted \\
\hline
\end{tabular}

\section{Conclusion}

As previously mentioned, the experiment was designed to take place between October 2019 and June 2020. However, at the end of February - beginning of March 2020, with the onset of the COVID-19 pandemic in Romania, we observed the situation in other countries but also that students started being reluctant to participate in the experimental programme, therefore we decided to end the experiment earlier by conducting the final tests shortly before the declaration of the state of emergency.

Given that special situation, although students responded promptly to our request to perform the final tests and thus help us complete our research, we could notice a state of discomfort among them, which might have been possible to influence their test results.

After processing and interpreting the results recorded by the control group, statistically significant differences between their initial and final tests were highlighted for Spirometry and Flamingo, which led us to reject the null hypotheses and accept the research hypotheses. Statistically insignificant differences between their initial and final tests were recorded for the Shuttle Run, the calculated significance threshold (p) being greater than 0.05 . This led us to accept the null hypothesis for this indicator and reject the alternative hypothesis.

It should be noted here that, unexpectedly, a higher progress rate was recorded in the control group compared to the experiment group for the Shuttle Run test, although the progress was not statistically significant. A possible explanation would be the psychological impact 
generated by the spread of the Coronavirus pandemic, the final test taking place under the pressure of events, as mentioned above, in the week before the declaration of the state of emergency. Another explanation might be the initial assumption of the experiment, which was also communicated to students, that we were not necessarily interested in their results and performance achieved as an outcome of training, but especially in their awareness of the importance of movement for health.

In the experiment group, statistically significant differences between their initial and final tests were recorded for two parameters out of three, namely vital capacity and static balance, which led us to reject the null hypotheses and accept the research hypotheses. Statistically insignificant differences between their initial and final tests were recorded for the Shuttle Run, which is why the null hypothesis was accepted.

We also compared the results achieved by the two groups in the final tests. Their average scores highlighted the existence of significant differences for two parameters, namely vital capacity and static balance. In the case of the Shuttle Run test, no significant differences were found between the two groups of participants.

Overall, taking into account the above, it can be concluded that the special aerobic gymnastics programmes designed by us to meet the needs of students with partial medical exemptions have proven their effectiveness in improving some motor and functional parameters, which confirms the first hypothesis of the research.

Student participation and involvement in our programmes were very good. After a start marked by some embarrassment caused by the lack of previous motor experience, the work atmosphere became increasingly positive and relaxed, being characterised by emotional readiness and desire for self-improvement. This allows us to consider that we have largely succeeded in reaching our main initial goal, specifically to meet the needs of students with partial medical exemptions through attractive and accessible exercise programmes able to reveal both their health benefits and arouse the pleasure of physical movement.

\section{Acknowledgement}

The experiment described in this paper is part of a more extensive research, which was the foundation of the author's $\mathrm{PhD}$ thesis. Other parts of this research have already been published.

\section{References}

European Commission. (2008). EU physical activity guidelines recommended policy actions in support of health-enhancing physical activity. Brussels.

https://ec.europa.eu/assets/eac/sport/library/policy_documents/eu-physical-activityguidelines-2008_en.pdf

European Commission. (2015). EU work plan for sport 2016-2017: Expert-group on healthenhancing physical activity. The Hague.

https://eacea.ec.europa.eu/sites/eacea-site/files/recommendations_pe_at_schools_2015.pdf

European Commission. (2018). New Eurobarometer on sport and physical activity. Brussels. https://ec.europa.eu/sport/news/2018/new-eurobarometer-sport-and-physical-activity_en

European Commission. (2007). White Paper on sport (COM 2007, 391 final). Brussels. https://eur-lex.europa.eu/legal-content/EN/TXT/?uri=LEGISSUM\%3A135010 
Feldman, D. E., Barnett, T. Shrier, I., Rossignol, M., \& Abenhaim, L. (2003). Is physical activity differentially associated with different types of sedentary pursuits? Archives of Pediatrics \& Adolescent Medicine, 157, 797-802. https://doi.org/10.1001/archpedi.157.8.797

Finkelstein, E. A., Fiebelkorn, I. C., \& Wang, G. (2003). National medical spending attributable to overweight and obesity: How much, and who's paying? Health Affairs (Suppl Web Exclusives), W3-219-226. https://doi.org/10.1377/hlthaff.w3.219

Guthold, R., Stevens, G. A., Riley, L. M., \& Bull, F. C. (2018). Worldwide trends in insufficient physical activity from 2001 to 2016: A pooled analysis of 358 population-based surveys with 1.9 million participants. Lancet Glob Health, 6(10), e1077-e1086. https://doi.org/10.1016/S2214-109X(18)30357-7

Helmrich, S. P., Ragland, D. R., Leung, R. W., \& Paffenbarger Jr., R. S. (1991). Physical activity and reduced occurrence of non-insulin-dependent diabetes mellitus. The New England Journal of Medicine, 325(3), 147-152. https://doi.org/10.1056/nejm199107183250302

Lear, S. A., Hu, W., Rangarajan, S., Gasevic, D., Leong, D., Iqbal, R., Casanova, A., Swaminathan, S., Anjana, R. M., Kumar, R., Rosengren, A., Wei, L., Yang, W., Chuanschi, W., Huaxing, L., Nair, S., Diaz, R., Swidon, H.,... Yusuf, S. (2017). The effect of physical activity on mortality and cardiovascular disease in 130000 people from 17 high-income, middle-income, and low-income countries: The PURE study. The Lancet, 390(10113), 2643-2654. https://doi.org/10.1016/s0140-6736(17)31634-3

Martin, S. A., Pence, B. D., \& Woods, J. A. (2009). Exercise and respiratory tract viral infections. Exercise and Sport Sciences Reviews, 37(4), 157-164. https://doi.org/10.1097/jes.0b013e3181b7b57b

Myers, J., Kaykha, A., George, S., Abella, J., Zaheer, N., Lear, S., Yamazaki, T., \& Froelicher, V. (2004). Fitness versus physical activity patterns in predicting mortality in men. American Journal of Medicine, 117(12), 912-918. https://doi.org/10.1016/j.amjmed.2004.06.047

Nieman, D. C., \& Wentz, L. M. (2019). The compelling link between physical activity and the body's defense system. Journal of Sport and Health Science, 8(3), 201-217. https://doi.org/10.1016/j.jshs.2018.09.009

Riebe, D., Franklin, B. A., Thompson, P. D., Garber, C. E., Whitfield, G. P., Magal, M., \& Pescatello, L. S. (2015). Updating ACSM's recommendations for exercise preparticipation health screening. Medicine \& Science in Sports \& Exercise, 47(11), 2473-2479. https://doi.org/10.1249/mss.0000000000000664

Sharif, I., \& Sargent, J. D. (2006). Association between television, movie, and video game exposure and school performance. Pediatrics, 118(4), e1061-1070. https://doi.org/10.1542/peds.2005-2854

Soares-Miranda, L., Siscovick, D. S., Psaty, B. M., Longstreth, W. T. Jr., \& Mozaffarian, D. (2016). Physical activity and risk of coronary heart disease and stroke in older adults: The cardiovascular health study. Circulation, 133(2), 147-155. https://doi.org/10.1161/circulationaha.115.018323

Wiklund, P. (2016). The role of physical activity and exercise in obesity and weight management: Time for critical appraisal. Journal of Sport and Health Science, 5(2), 151154. https://doi.org/10.1016/j.jshs.2016.04.001 